Practical Recommendations for Considering Culture, Race, and Ethnicity in Personality Psychology

Forthcoming at Social and Personality Psychology Compass

\author{
Memoona Arshad ${ }^{1}$ \\ Joanne M. Chung ${ }^{2}$ \\ ${ }^{1}$ Department of Psychology, York University \\ ${ }^{2}$ Department of Psychology, University of Toronto, Mississauga
}

\begin{abstract}
Author Note
Memoona Arshad https://orcid.org/0000-0002-0704-3156

Joanne M. Chung https://orcid.org/0000-0002-2191-9644
\end{abstract}

We would like to thank Sanaz Talaifar, Rick Robins, Jin X. Goh, and Amber Thalmayer for their helpful feedback on this manuscript.

Correspondence regarding this manuscript may be directed to Memoona Arshad. Email: arshad.memoonaa@gmail.com. 


\begin{abstract}
Personality science is the study of the individual. It aims to understand what makes people similar to others, different from some, and unique to themselves. However, there is room for research in personality to more thoughtfully consider culture, race, and ethnicity in order to better understand individual differences in people's patterns of thinking, feeling, and behaving. High impact personality journals rarely include such factors into the interpretation of results, and cross-cultural and ethnic minority publications are limited within the discipline. This paper offers a brief, non-exhaustive overview of how culture, race, and ethnicity are examined in relation to personality, showing that: 1) social structures continue to be neglected in the research, 2) we can learn from research being conducted in neighboring areas, and 3) valuable work is already being done within personality psychology. We offer recommendations that emphasize community based participatory research methods, combined etic-emic approaches, and contextualizing research findings to improve the consideration of culture, race, and ethnicity in personality research.
\end{abstract}

Keywords: personality, culture, race, ethnicity, combined etic-emic approach, daily life, community based participatory research 


\section{Practical Recommendations for Considering Culture, Race, and Ethnicity in Personality Psychology}

Personality science seeks to understand what makes people similar to others, different from some, and unique to themselves. These questions require looking at the range of people's experiences, including factors related to culture, race, and ethnicity. This is to not only increase the generalizability of our research, but also to understand human personality from a lens that does not prioritize the mainstream majority (King, 2021). Yet, studies that carefully consider these factors are relatively rare within personality psychology. This is a problem that is not exclusive to personality psychology, as psychological science in general has tended towards excluding people from underrepresented groups (Espinosa \& Verney, 2020; Hall, Yip, \& Zárate, 2016; Henrich, Heine, \& Norenzayan, 2010; Saucier \& Thalmayer, 2012; Syed et al., 2018).There have been calls for research that more carefully considers culture, race, and ethnicity in personality psychology, and this has been viewed as a much needed avenue for scholars to engage with real world issues (Dupree \& Boykin, 2021; King, 2021; Roberts et al., 2020), especially because resources are more widely available (e.g., open materials and data, frameworks for conducting collaborative research, and funding geared towards addressing societal problems).

Additionally, a raised consciousness about injustices that marginalized people have experienced and continue to experience (e.g., global protests in response to the killing of George Floyd; King, Lee, \& Kaleem, 2020; Nguyen et al., 2021) further highlights the need to address these factors in personality psychology. Debates about who should conduct research focused on communities of colour and other underrepresented groups often place the responsibility on researchers from those groups (Dupree \& Boykin, 2021; Milner, 2007), or those who already 
recognize the importance of such research. However, all researchers should work to acknowledge their own positionality and awareness of culture, race, and ethnicity to circumvent harmful stereotypes or misconceptions of individuals and communities, regardless of whether they explicitly study these factors in their research (Milner, 2007; Cheon, Melani, \& Hong, 2020; Roberts et al., 2020). We think that personality psychology especially should and can grow in this regard. In this paper, we briefly review some approaches from neighboring areas within psychology, highlight work that is already being conducted within personality psychology, and provide initial, practical recommendations for researchers who are interested in incorporating a consideration of culture, race, and ethnicity into personality science in meaningful ways.

\section{What is Culture, Race, and Ethnicity?}

The idea that psychology has centered the experiences of WEIRD (Western, Educated, Industrialized, Rich, and Democratic) people (Espinosa \& Verney, 2020; Henrich et al., 2010; Saucier \& Thalmayer, 2012) is not new, however it remains an issue today. Furthermore, people from multicultural and minority populations, including racial and ethnic minorities, have been historically excluded from research studies in psychological research (e.g., Hall et al., 2016; Syed et al., 2018). Race and ethnicity are closely related to the concept of culture, and while often used interchangeably in the research literature, are distinct from each other (Causadias et al., 2018; Hall et al., 2016). Although some people hold the lay belief that race is biological (e.g., as examined in Plaks et al., 2012; Williams \& Eberhardt, 2008), we refer to it as a social construct that groups people together via shared physical characteristics, such as skin colour. Racial differences between people are often created by dominant groups in a society to denote worth or hierarchy of minority group members. In turn, this categorization can have profound effects on the psychology of people, because it includes others' perceptions of them, through 
generalizations and stereotypes, which can then influence their racial identity development positively or negatively (Betancourt \& López, 1993; Roberts et al., 2020; Utsey et al., 2008). Ethnicity, in contrast, is a social grouping of individuals that share common nationality, language, history, traditions, and cultural practices (Betancourt \& López, 1993; Golash-Boza, 2016; Markus, 2008). Race and ethnicity are integrated into the idea of culture, as they all operate at individual and group (e.g., societal) levels and are used by people to organize and distinguish communities (Causadias et al., 2018; Betancourt \& López, 1993; Markus, 2008). As such, culture is defined as a learned and shared system of meanings (i.e., beliefs \& values) that are transmitted through shared activities, change over time, and are shaped by people to construct, define, and interpret the world around them (Markus, 2008; Matsumoto et al., 1996; Rohner, 1984).

\section{Culture, Race, and Ethnicity Matter for the Understanding of Personality}

People's cultural, racial, and ethnic heritage can impact their access to resources, their socioeconomic status, and prospects for social mobility (e.g., Feinstein, 1993; Manstead, 2018; Williams et al., 2010) via experiences with social structures. Social structures refer to relations between individual members and societal institutions (e.g., political and educational entities, social services) that organize and assign value to social categories, such as race, ethnicity, gender, and class (e.g., Cortina, Curtin, \& Stewart, 2012). These variables interact hierarchically to create systems of privilege and disadvantage (Cortina et al., 2012; Mullings \& Schulz, 2006). Racial and ethnic stereotypes, upheld through dominant institutions in society, including the government and media, can negatively impact people's access to educational (Manly et al., 2002), occupational (Emerson \& Murphy, 2014) and health care (Glymour \& Manly, 2008) resources. In turn, different aspects of people's personalities can be affected through forces of 
racism and oppression (e.g., Chávez et al., 2008; Cortina et al., 2012). Because social structures affect people (e.g., Cortina et al., 2012), including samples of people that have been historically excluded in personality psychology is essential for understanding individual differences and personality processes. This is becoming increasingly important as the number of those who identify as racial and ethnic minorities grows; for example, in Canada, racial and ethnic minorities are expected to make up between $35 \%$ to $38 \%$ of the population by 2036 , and in the United States, over 50\% of the population by 2044 (Espinosa \& Verney, 2020; Morency et al., $2017)^{1}$.

Additionally, focusing on social structures in personality psychology creates an opportunity for researchers to explicitly consider the role of contextual factors in relation to individuals' personalities. For example, some studies indicate that individuals' expression of their personality and self-views differ across different relationships and positions in society (e.g., Clifton, 2014; Roberts, 2007, Suh, 2002). In other studies, social contextual factors of socioeconomic status (SES), family environment, and discrimination have been shown to be important for the development of Mexican American adolescents' self-regulation and life satisfaction (e.g., Atherton, Lawson, \& Robins, 2020; Willroth, Atherton, \& Robins, 2021). Findings also indicate geographical variations in Big Five personality traits, highlighting how contextual factors, such as racial diversity, community development, and crime rate, are

\footnotetext{
${ }^{1}$ Here, we specifically focus on providing recommendations for increasing considerations for race, ethnicity, and culture in personality psychology, while acknowledging that there are other factors that continue to be understudied in personality psychology, and psychology more generally. Low-income individuals, people from 2SLGBTQIA+ communities, and people with disabilities are some examples of people that have been historically excluded (Espinosa \& Verney, 2020; Henrich et al., 2010; Syed \& Kathawalla, 2020). It is important to note that these factors often interact. For example, an individual can simultaneously identify or be perceived by others as belonging to several groups (e.g., a cisgender, heterosexual, Asian woman), resulting in having different advantages and disadvantages in society, referred to as intersectionality (Combahee River Collective, 2005; Crenshaw, 1989; Henderson, 1997). We hope that in improving our consideration of culture, race, and ethnicity, and thus acknowledging social structures, that intersectionality in relation to personality processes may be attended to in the future.
} 
negatively (i.e., low racial diversity, high crime rate) and positively (i.e., established community centres/resources) associated with how people think, feel, and behave within and across countries (e.g., Rentfrow, Gosling, \& Potter, 2008; Rentfrow \& Jokela, 2016). These examples show that the examination of many constructs examined in personality research can benefit from the consideration of factors related to culture, race, and ethnicity (e.g., Lui et al., 2016).

\section{A Consideration of Culture, Race, and Ethnicity Can Improve Personality Research}

Incorporating a consideration of culture, race, and ethnicity in personality psychology can help researchers improve their research because it helps to contextualize it. One benefit to doing so is that it can appropriately constrain researchers to be careful about making blanket statements about their findings, for example, about the adaptiveness of certain aspects of personality over others and the universal applicability of Big Five personality traits, by making sure readers are reminded of sample characteristics, rationale and assumptions behind the methods used, and any other constraints on generality (Simons, Shoda, \& Lindsay, 2017). Moreover, considering these factors also allows us to revisit the generalizability of previous and current personality research. Including samples of underrepresented people challenges personality researchers to justify their samples and make clear the relevance of their findings to people from the group in question instead of providing vague, general statements about a larger unrelated population. For example, with the implicit assumption that American samples are White (Devos \& Banaji, 2005), studies on non-White American samples are labeled as "cultural" studies and are seen as less generalizable (Cheon et al., 2020). This serves the assumption that research on White Americans is more generalizable than research on non-White Americans (Cheon et al., 2020), and challenges researchers to be more explicit about the replicability and credibility of their findings. It is important to note that this is an issue related to race within a country, and that issues related 
to representation across countries may present themselves differently (e.g., van de Vijver, 2013). While personality psychology has been at the forefront of the credibility revolution (Atherton et al., 2021), the relative lack of regard for culture, race, and ethnicity within the field is an issue for replicability as well. The ways in which researchers recruit and study individuals should ensure findings can be generalizable because generalizability influences the perceived impact and credibility of the research (Cheon et al., 2020; Simons et al., 2017). Moving forward, improving the representation of underrecruited samples in personality research should be just as important to researchers as are open science approaches and preregistrations, especially as generalizability constraints are not limited to "cultural" studies but apply to Western research as well (Cheon et al., 2020).

\section{Personality Psychology Currently Lacks Research on Culture, Race and Ethnicity}

Personality psychology has historically focused on a narrow population, as part of its beginnings was focused on assessing the intelligence and ability of White men in the military (e.g., Gibby \& Zickar, 2008; Winter \& Barenbaum, 1999). Personality psychology has broadened in its scope, yet, culture, race, and ethnicity are still understudied.

In a recent commentary, Atherton et al. (2021) reported a search of the 50 most cited articles that use personality as a keyword, and the results showed that studies used samples predominantly composed of American undergraduate students, and were authored almost entirely by individuals in the Western world. These results suggest that researchers in personality psychology should orient themselves towards more meaningfully addressing culture in their work by conducting and prioritizing work that uses non-Western samples.

Additionally, in a notable commentary on the current state of personality psychology that in part motivates the current work, Syed (2021) highlights the relative absence of race, ethnicity, 
and culture in personality research, specifically identifying the exclusion of structural considerations (e.g., power, privilege, and context) in understanding personality. In doing so, Syed (2021) emphasizes that personality encompasses more than just traits and should include a consideration of structural contexts and social structures, concepts that are relatively rare within personality psychology.

For example, in one important review Cortina et al. (2012) examined the number of empirical articles in three leading journals in personality psychology (i.e., Journal of Research in Personality (JRP), Journal of Personality (JP), and Journal of Personality and Social Psychology: Personality Processes and Individual Differences (JPSP) section that focused on race, ethnicity, and other variables such as gender, class and sexual orientation. Among these journals, only three percent of the JPSP articles acknowledged race or ethnicity in the interpretation of results (and none in either JRP or JP; Cortina et al., 2012). This neglect of social structures was not reflected in psychology journals that have a special focus on race and ethnicity (i.e., Cultural Diversity and Ethnic Minority Psychology, The Journal of Black Psychology, and The Hispanic Journal of Behavioral Sciences). Cortina et al. (2012) found that the majority of articles in each of these journals examined social structures in the study of personality. This suggests that although advances in understanding the relations between personality and social structures are being addressed, they are not reaching a larger audience (i.e., mainstream personality psychologists) who might greatly benefit from this work (Cortina et al., 2012).

\section{Broadening to Other Areas of Psychology}

Others who have reviewed the literature have shown that a consideration of culture, race, and ethnicity is lacking more generally in psychology (e.g., Arnett, 2008; Hartmann et al., 2013; Roberts et al., 2020; Thalmayer, Toscanelli, \& Arnett., 2021). These reviews investigated the 
presence of diverse research samples in prominent psychology journals (Arnett, 2008; Thalmayer et al, 2021), trends for ethnic-minority and cross-cultural publications indexed in PsycINFO (Hartmann et al., 2013) and the frequency of research publications highlighting race, with an additional focus on race of authors and editors (Roberts et al., 2020). Research samples in psychology continue to be predominantly from Western, English-speaking countries (Arnett, 2008; Thalmayer et al., 2021), publications using cross-cultural and ethnic minority perspectives are limited in APA journals (Hartmann et al., 2013), and the majority of articles published in high impact psychology journals do not highlight race as an issue of interest, while the ones that do are mostly edited and written by White people who recruit fewer participants of colour in their participant samples (Roberts et al., 2020). This suggests that considerations of race, ethnicity, and culture are not seen as important in mainstream, high-impact journals, and works to further devalue the work of researchers who highlight these issues.

\section{Conceptualizations of Personality Already Include Culture, Race, and Ethnicity}

A pervasive view of personality psychology is that it is restricted to the Big Five personality dimensions where traits are evidence of one's personality. However, in addition to our recommendations about contextualizing personality, there are other approaches to studying personality, including the three-level organizational system (McAdams, 1995, McAdams \& Pals, 2006; see Syed, 2021 for a more detailed treatment of this approach). This approach makes room for an examination of personality in relation to culture, race, and ethnicity, for example, with regard to characteristic adaptations as they are situated in specific contexts and are shaped by social experiences, and life narratives because they allow individuals to share how they make meaning of their cultural experiences in their own words (McAdams \& Pals, 2006). 
Furthermore, there has been a recent increase in research focused on personality dynamics, which examines processes, mechanisms, and changes that are integral to the expression of and changes in personality (e.g., Kuper et al., 2021). One of the reasons for the renewed attention on personality dynamics is the increased availability of technology (e.g., smartphones and wearables) related to daily life methods. Daily life methods (Bolger, Davis, \& Rafaeli, 2003) have typically been lauded for being more ecologically valid than other methodologies such as questionnaires and interviews because they allow for people to engage with a research study in situ over time (Allemand \& Mehl, 2017), for example, by responding to a push notification on their smartphone. Although not often specifically discussed in this context, daily life methods hold special promise for examining how personality processes are related to different aspects of culture, race, and ethnicity via the structural contexts individuals exist in. We can learn from work that is already being done on the relations between daily experiences of racial discrimination and well-being outcomes in ethnic minority individuals (e.g., Seaton et al., 2018; Seaton, 2019), highlighting the utility of daily life studies for offering a unique window into the effects of racial discrimination in everyday life, as well as in the long term (Hoggard, Byrd, and Sellers, 2012 and 2015; Ong, Burrow, Fuller-Rowell, Ja, \& Sue, 2013; Ong, FullerRowell, and Burrow, 2009; Seaton \& Douglass, 2014).

\section{What is Already Being Done in Other Areas of Psychology?}

Personality psychology can make improvements in considering culture, race, and ethnicity by looking at how neighboring areas have done so. In Table 1, we provide a broad and simplified overview based on our knowledge of these areas. ${ }^{2}$

\footnotetext{
${ }^{2}$ We provide a basic overview while recognizing that the lines among these areas are often fuzzy. We also emphasize these specific areas while acknowledging that each area interplays with social psychology.
} 


\section{Table 1.}

Broad Overview of How Neighboring Areas in Psychology Consider Culture, Race, and Ethnicity

\begin{tabular}{|c|c|c|}
\hline $\begin{array}{l}\text { Area in } \\
\text { Psychology }\end{array}$ & How culture, race, and ethnicity are considered & Example(s) \\
\hline $\begin{array}{l}\text { Cross-cultural } \\
\text { psychology }\end{array}$ & $\begin{array}{l}\text { Explicit consideration of culture in relation to } \\
\text { thoughts, feelings, and behavior; focus is on } \\
\text { similarities in } 2 \text { or more cultures (van de Vijver, } \\
\text { Leung, \& Leung, 1997) }\end{array}$ & $\begin{array}{l}\text { The extent to which there are similarities on linguistic, functional, } \\
\text { conceptual, and metric criteria in different cultural groups that are being } \\
\text { compared (e.g., Leong, Leung, \& Cheung, 2010) } \\
\text { Etic approach: import construct and measure from one cultural context to } \\
\text { another (e.g., Berry, 1989; Cheung, van de Vijver, \& Leong., 2011; } \\
\text { Cheung, 2012; Fetvadjiev \& van de Vijver, 2015) }\end{array}$ \\
\hline $\begin{array}{l}\text { Cultural } \\
\text { psychology }\end{array}$ & $\begin{array}{l}\text { Explicit consideration of culture in relation to } \\
\text { thoughts, feelings, and behavior; comparison is } \\
\text { not the primary goal }\end{array}$ & $\begin{array}{l}\text { Emic approach: consider construct and measure within cultural context of } \\
\text { interest (e.g., Berry, 1989; Cheung et al., 2011; Cheung, 2012; Fetvadjiev } \\
\& \text { van de Vijver, 2015) }\end{array}$ \\
\hline $\begin{array}{l}\text { Ethnic minority } \\
\text { psychology }\end{array}$ & $\begin{array}{l}\text { Focus on psychology of people from historically } \\
\text { marginalized racial and ethnic groups (e.g., Hall } \\
\text { et al., 2016) }\end{array}$ & $\begin{array}{l}\text { Examining instances of racial discrimination (e.g., Seaton et al., 2018) } \\
\text { using experience sampling studies (e.g., Bolger et al.,2003) }\end{array}$ \\
\hline $\begin{array}{l}\text { Community } \\
\text { psychology }\end{array}$ & $\begin{array}{l}\text { Joint consideration of person and community } \\
\text { factors (including to promote positive social } \\
\text { change) }\end{array}$ & $\begin{array}{l}\text { Community based participatory research: Proactively assessing } \\
\text { community resources, structures, and power dynamics in combination } \\
\text { with partnering with community members at each stage of the research } \\
\text { process (e.g., Collins et al., 2018; Espinosa \& Verney, 2020) }\end{array}$ \\
\hline $\begin{array}{l}\text { Developmental } \\
\text { psychology }\end{array}$ & $\begin{array}{l}\text { Examination of culture, race, and ethnicity as } \\
\text { proxies of important contextual factors for } \\
\text { change (e.g., Quintana et al., 2007) }\end{array}$ & $\begin{array}{l}\text { Integrative model: Examine institutional racism, positionality, cultural } \\
\text { practices in relation to risk and resilience factors in ethnic minority } \\
\text { children (García Coll et al., 1996) }\end{array}$ \\
\hline
\end{tabular}

Table 1 includes a description of areas in psychology already doing work that emphasizes culture, race, and ethnicity in thoughtful ways. Personality psychologists can acknowledge and learn from this work to expand their own theoretical and methodological toolboxes.

Another approach for improving personality psychology's treatment of culture, race, and ethnicity is to take a closer look at studies that are being conducted within the realm of personality psychology. See Table 2 for a summary of five studies that we think meaningfully highlight the link between culture and personality in different ways. 
Table 2.

Summary of Recent Studies in Personality Psychology That Meaningfully Consider Culture

Citation

Khwaja, Vaid,

Zannone, Harari

Faisal \& Matic

(2019)

Purpose of the study

Examine extent to which mobile sensing data could be used

to predict people's standing (e.g., low or high) on self-

reported Big Five traits in sample of participants from

United Kingdom, Spain, Chile, Peru, and Colombia

Thalmayer, Job,

Shino, Robinson,

Saucier $(2020)$

\section{Examine personality descriptors in the Khoekhoegowab}

language in people living in Sub-Saharan Africa and test the

universality of the Big Five and other proposed univers

models in a culturally distant sample of community

members in southern Africa.

Cheung, Kube, Tay, Examine impact of the Syrian conflict on well-being of

Diener, Jackson,

and 2016 Lucas, Ni, \& Leung and 2016
How culture is considered

Used machine learning to specify personality classification models

based on smartphone data features (i.e., accelerometer, pedometer,

battery usage, ambient noise, etc.)

Specified: 1) a model that was trained on all possible combinations of data from four countries, and then tested on data from fifth country; 2) a model that was trained on a subset of data within each country, and then tested on the other part.

Examined Khoekhoe descriptors that came from a dictionary in Exarion with descriptors from studies conducted in North America.

Asked participants to report on someone they knew on advice of loca collaborators who shared that people who spoke Khoekohoegowab might not typically describe their own qualities.

Teachers of Khoekhoegowab helped to recruit participants, and also administered the questionnaire in a face-to-face setting to allow for participants who were not fluent in reading and writing the language to be included.

Used semi-structured interviews to follow up on quantitative results.

People's open-ended responses featured in the manuscript.

Preregistration, open materials, and transparent reporting about procedures were also used.

Provide details about the events in Syria, including the Arab Sprin displacement, and forced migration that has occurred since then

Compare measures of social support and well-being in Syrian people (pre-and-post conflict) to well-being in people across the rest of the world.
Why it is important

Illustration of how etic and emic approache an be used in combination with behavioral methods used to study daily life

Illustration of combined etic-emic approach

Demonstration of how collaboration can occur with people who are members of the community.

Illustration of how the research team was able to clarify and update interpretations of meanings of descriptors that seemed mbiguous based on their definition in the English language.

Illustration of how open science methods can be used in combination with careful

consideration of culture.

Example of how authors can effectively situate the sample into historical, social, and cultural contexts.

Illustration of combined etic-emic approach to show that the decrease in well-being is most significant for Syrian people relative to the rest of the world. 
Chung, Meijer, Zonneveld, Sawaf, Alajak, Moopen ...

Laceulle (2021)

$\begin{array}{ll}\text { Atherton, Lawson, \& } & \text { Examine developmental antecedents of stability and change } \\ \text { Robins (2020) } & \text { in the construct of effortful control from late childhood to }\end{array}$ adults who have resettled in the Netherlands young adulthood in Mexican-origin youth living in the United States
Examine emotions and personality change in Syrian young Included Syrian people and bilingual Arabic-English speakers in

Included Syrian people and bilingual Arabic-English speakers in
research team. Consulted with a Cultural Advisory Board to ens research team. Consulted with a Cultural Advisory Board
appropriateness of methodology and research materials.

Translated and adapted research materials using a back translation process. Coding open-ended and behavioral data in Arabic.

Created additional opportunities for participants (e.g., newsletters with accompanying small gifts following each data collection,

celebratory event facilitated by team members, workshop series for participants, electronic book of participants' artwork to be shared with Dutch and international communities).

Plan to create summaries of scholarly output in Dutch and Arabic to allow participants to engage with the findings from study.

Considered cultural systems specific to sample of Mexican-origin youth, such as nativity status, perceived ethnic discrimination, and Mexican cultural values.

Applied Bronfenbrenner's (1979) ecological systems theory, examining multiple environmental factors to provide a holistic view on personality development.

Used culturally specific questionnaires in combination with measures Illustration of combined etic-emic approach not tailored for Mexican-origin youth.
Example of how people from the community can become involved with psychological research

Example of using research methods that allow for discussions about constructs that emerge in Arabic language and Syrian culture

Illustration of how participation can be enriched beyond monetary compensation.

Example of how scientific findings can be

communicated to the community.

Illustration of how social contextual factors are important for studying personality development.

Importance of examining environmental and cultural variables in relation to effortful control of ethnic minorities. 
Table 2 includes descriptions of studies that have meaningfully considered culture within personality psychology, but also indicates the relative absence of considering race and ethnicity within the field (e.g., Syed, 2021) raised in our earlier discussion of the current state of personality research. Thus, future research in personality psychology might use these extant studies as examples for more deeply considering culture, but more work is clearly needed regarding race and ethnicity.

\section{Recommendations for Considering Culture, Race, and Ethnicity in Personality Psychology}

After reviewing what is being done in neighboring areas of psychology and within personality psychology, we have a few recommendations for researchers who are interested in more carefully considering culture, race, and ethnicity in the planning, implementation and reporting of their work ${ }^{3}$. We group recommendations by study phase in Figure 1.

\footnotetext{
${ }^{3}$ We also acknowledge that researchers serve in multiple roles in the field, e.g., as stakeholders, editors, and reviewers, and hope that our recommendations can stimulate thinking about how to increase representation in these roles in the future.
} 
Figure 1.

Recommendations for Considering Culture, Race, and Ethnicity in Personality Psychology
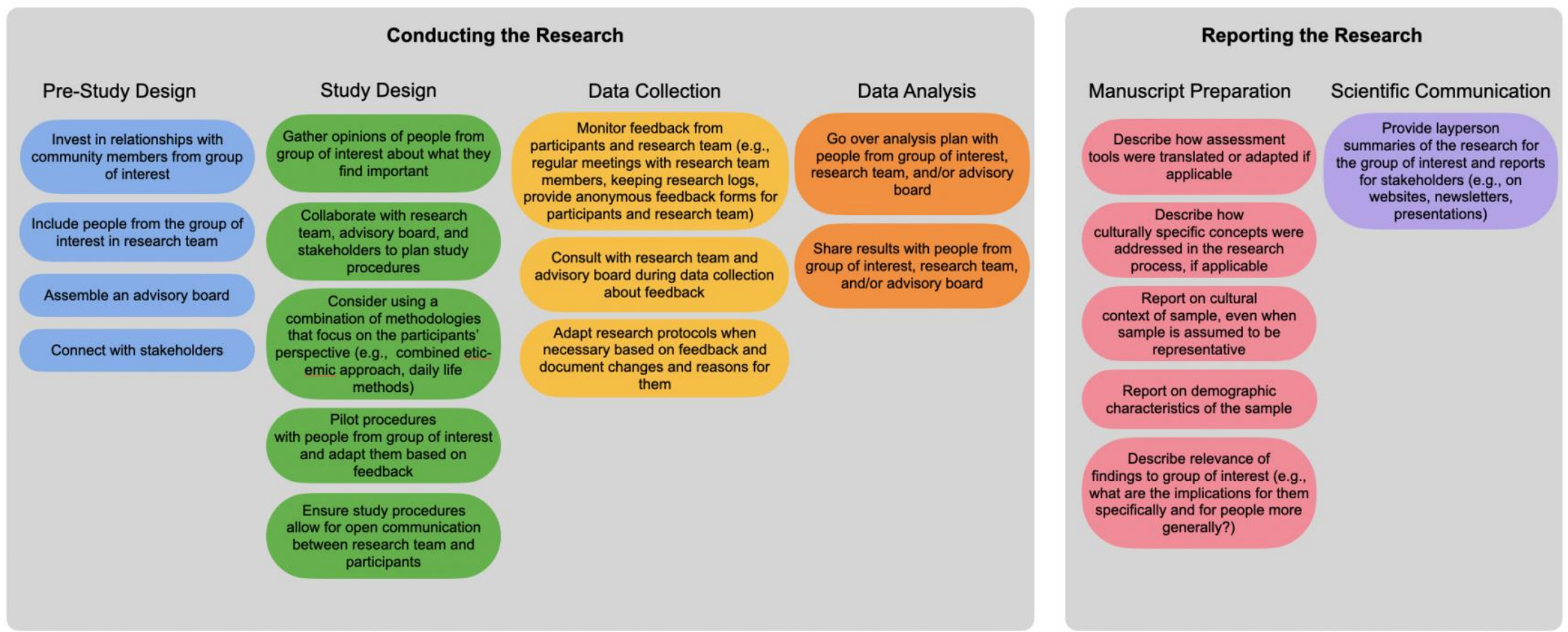
Figure 1 includes our recommendations for meaningfully considering culture, race, and ethnicity in personality psychology. In our recommendations we emphasize connecting and collaborating with people from the group and/or community of interest. Community Based Participatory Research (CBPR) methods have been used in indigenization of psychology movements in South America, Africa and Asia, in addition to applied settings within social and organizational psychology. CBPR methods work as a tool to foster community action (Collins et al., 2018) and provide an approach that allows for a more horizontal exchange between researchers and community members (e.g., Balls-Berry \& Acosta-Pérez, 2017; Espinosa \& Verney, 2020). CBPR methods can be used at any stage in the research process, including building important relationships with people from the community of interest before designing the study (e.g., using focus groups), providing opportunities for feedback throughout the data collection process (e.g., through frequent meetings with the research team), and interpreting study results with the team to facilitate appropriate interpretation before sharing them with both the scientific and layperson communities. For an excellent overview of CBPR methods in psychology, see Collins et al., 2018. One implementation of CBPR is to use an advisory board, where individuals who have lived experiences being part of the community of interest are included and can provide guidance on issues such as the appropriateness of the study materials, participant recruitment, and the study procedure. In general, a benefit of having community members involved in the research process is that research protocols can be piloted and/or altered based on feedback, likely increasing the study's reach.

Our recommendations also advocate for the use of mixed methods that can address both universal and culturally specific aspects of psychological constructs (e.g., Cheung et al., 2011; Silan, 2020; Thalmayer et al., 2020). For example, with regard to questionnaires, both close- 
ended and open-ended questions can be administered, with open-ended questions allowing participants to provide feedback on their experience with the task, and to share any additional information they feel is important. Daily life methods (Allemand \& Mehl, 2017; Bolger et al., 2003) can also be used to further assess how people encounter social structures in everyday life (e.g., Seaton et al., 2018). We also recommend that where translation of items is needed, researchers use a multi-step process including expert panels, in addition to methods such as forward-back translation(e.g., World Health Organization guidelines on translation; http://www.who.int/substance_abuse/research_tools/translation/en/). Additionally, providing information regarding the cultural context of the sample, regardless of the assumed representativeness of the sample, can help to change norms for how mainstream personality psychology considers culture, race, and ethnicity. For example, what is the population that the sample is drawn from like with regards to norms, beliefs, and cultural practices? What historical, social, and cultural factors should the reader know about to contextualize their interpretation of the study results (e.g., Muthukrishna. Henrich, \& Slingerland, 2021; Sullivan, 2020)?

\section{Discussion}

Overall, our recommendations provide some avenues for researchers to carefully consider race, ethnicity, and culture in their work. However, there are also larger, systemic factors at play that must be acknowledged in the goal to improve personality research. For one, incentives for academic publishing and job security in the field can discourage researchers from incorporating a consideration of race, ethnicity, and culture into their research. The work researchers conduct on racialized topics is less likely to be funded and publicized, contributing to fewer studies that use this approach being published in higher impact journals (Dupree \& Boykin, 2021). 
Moreover, the majority of researchers who write, edit, and publish work that highlights race tend to be White, despite authors of colour being more invested in communities of colour and racial diversity (Roberts et al., 2020). These factors combined can contribute to the lack of diverse representation in psychology, as people who want to conduct meaningful research on race, ethnicity, and culture may not find value in their work, or feel able to progress through academia with research that is seen as niche and specialized. However, opportunities can be created here to promote diverse work in psychology. Including people in the research team who are members of the group we are interested in learning about can lead to opportunities for training, opening doors for them to pursue scholarly research in the future. We recommend that editors, grant panelists, and those in other positions of power, work to improve racial diversity in psychological research (e.g., Roberts et al., 2020) and develop practices to reduce racial inequality in academia (e.g., Dupree \& Boykin, 2021) to increase representation of these issues more broadly across the area of personality psychology. For example, editors of personality psychology journals could initiate special issues devoted to culture, race, and ethnicity in personality psychology. Additionally, grant agencies could create funding opportunities for such research. Furthermore, professional societies that focus on personality psychology could create awards that recognize scholarship in these areas.

Finally, we want to acknowledge that not all researchers will be particularly interested, or able to, incorporate the provided recommendations to their work. We encourage those who claim to be uninterested to think about how their positionality (e.g., with regard to the researcher's gender, race, SES, social status, and life experiences) can impact the way they approach their own research activities (Milner, 2007). Additionally, we urge those individuals that hold positions of power to interrogate how their disinterest may shape or hinder certain research 
programs focused on culture, race, and ethnicity within personality psychology. For those who do not have access to resources (e.g., diverse samples, funding, data), we encourage reflecting on tasks that are attainable, such as reporting demographic characteristics in data, and making use of online repositories. For example, the Personality Development Collaborative (https://www.personalitydevelopmentcollaborative.org/) is a tool for researchers that allows one to share and use existing longitudinal data to study personality development. There are also additional panel datasets that allow for the examination of personality using non-Western samples (Atherton et al., 2021), for example, the Survey of Midlife Development in Japan (Markus, Coe, Ryff, Karasawa, Kawakami, \& Kitayama, 2009-2010), the Indonesian Family Life Study (RAND, n.d.), the Chinese Family Panel Study (Institute of Social Science Survey, 2015), and the Korean Longitudinal Survey of Women and Families (Joo, 2007-2016). These resources provide opportunities to those without access to diverse samples or funding to incorporate a consideration of culture, race, and ethnicity, in their work.

Personality psychologists have much to do to improve their consideration of race, ethnicity, and culture. This paper has provided a brief, non-exhaustive overview of the current state of personality science, as well as psychology more broadly. However, this is not to say that culture, race, and ethnicity are missing in personality research. Rather, when they are considered, many researchers do not adequately address people's lived experiences and community needs. Without contextualizing our work, or including historically underrepresented people in the research process, we are unable to appropriately conduct and interpret our research. Individuals exist in contexts, and identities across gender, class, race, ethnicity, and culture, (often working simultaneously) can shape the experiences of people in unique ways. If we are interested in individuals' identities, lived experiences, and personality processes, but continue to neglect 
including the experiences of people from some groups in our research, we are doing our field a disservice. The future of personality research must be developed with contributions from researchers with unique perspectives and a commitment to including underrepresented minorities, in order to improve research and make it applicable to more people. 


\section{References}

Allemand, M., \& Mehl, M. R. (2017). Personality assessment in daily life: A roadmap for future personality development research. In Personality development across the lifespan (pp. 437-454). Academic Press, an imprint of Elsevier. https://doi.org/https://doi.org/10.1016/B978-0-12-804674-6.00027-2

Arnett, J. J. (2008). The neglected 95\%: why American psychology needs to become less American. American Psychologist, 63, 602-614. https://doi.org/10.1037/0003-066X.63.7.602

Atherton, O. E., Lawson, K. M., \& Robins, R. W. (2020). The development of effortful control from late childhood to young adulthood. Journal of Personality and Social Psychology, 119, 417-456. https://doi.org/10.1037/pspp0000283

Atherton, O. E., Chung, J. M., Harris, K., Rohrer, J. M., Condon, D. M., Cheung, F., Vazire, S., Lucas, R. E., Donnellan, M. B., Mroczek, D. K., Soto, C. J., Antonoplis, S., Damian, R. I., Funder, D. C., Srivastava, S., Fraley, R. C., Jach, H., Roberts, B. W., Smillie, L. D., Sun, J., Tackett, J. L., Weston, S. J., Harden, K. P., \& Corker, K. S. (2021). Why Has Personality Psychology Played an Outsized Role in the Credibility Revolution?. Personality Science, 2(1), 1-21. https://doi.org/10.5964/ps.6001

Balls-Berry, J. E., \& Acosta-Pérez, E. (2017). The use of community engaged research principles to improve health: Community academic partnerships for research. Puerto Rico Health Sciences Journal, 36, 84-85.

Berry, J. W. (1989). Imposed etics-emics-derived etics: The operationalization of a compelling idea. International Journal of Psychology, 24, 721735. https://doi.org/10.1080/00207598908247841 
Betancourt, H., \& López, S. R. (1993). The study of culture, ethnicity, and race in American psychology. American Psychologist, 48, 629-637.

https://doi.org/10.1037/0003-066x.48.6.629

Bolger, N., Davis, A., \& Rafaeli, E. (2003). Diary methods: Capturing life as it is lived. Annual Review of Psychology, 54(1), 579-616. https://doi.org/10.1146/annurev.psych.54.101601.145030

Causadias, J. M., Vitriol, J. A., \& Atkin, A. L. (2018). Do we overemphasize the role of culture in the behavior of racial/ethnic minorities? Evidence of a cultural (mis)attribution bias in American psychology. American Psychologist, 73, 243-255.

https://doi.org/10.1037/amp0000099

Chávez, V., Duran, B., Baker, Q. E., Avila, M. M., \& Wallerstein, N. (2008). Chapter 5: The dance of race and privilege in CBPR. In Community-Based Participatory Research for Health: From Process to Outcomes (2nd ed., pp. 91-106). Jossey Bass Inc.

Cheon, B. K., Melani, I., \& Hong, Y. (2020). How USA-centric is psychology? An archival study of implicit assumptions of generalizability of findings to human nature based on origins of study samples. Social Psychological and Personality Science, 11, 928937. https://doi.org/10.1177/1948550620927269

Cheung F. M. (2012). Mainstreaming culture in psychology. The American Psychologist, 67, 721-730. https://doi.org/10.1037/a0029876

Cheung, F., Kube, A., Tay, L., Diener, E., Jackson, J. J., Lucas, R. E., Ni, M. Y., \& Leung, G. M. (2020). The impact of the Syrian conflict on population well-being. Nature Communications, 11(1), 3899. https://doi.org/10.1038/s41467-020-17369-0

Cheung, F. M., van de Vijver, F., \& Leong, F. T. L. (2011). Toward a new approach to the study 
of personality in culture. American Psychologist, 66, 593-603. https://doi.org/10.1037/a0022389

Chung, J. M., Meijer, L., Zonneveld, R., Sawaf, Z. A., Alajak, K., Moopen, N., ... Laceulle, O. (2021, February 16). Initial insights from a study of emotions and positive personality change in Syrian origin young adults who have recently resettled in the Netherlands. https://doi.org/10.31234/osf.io/xvqrs

Clifton A. (2014). Variability in personality expression across contexts: a social network approach. Journal of personality, 82, 103-115. https://doi.org/10.1111/jopy.12038

Collins, S. E., Clifasefi, S. L., Stanton, J., The Leap Advisory Board, Straits, K., GilKashiwabara, E., Rodriguez Espinosa, P., Nicasio, A. V., Andrasik, M. P., Hawes, S. M., Miller, K. A., Nelson, L. A., Orfaly, V. E., Duran, B. M., \& Wallerstein, N. (2018). Community-based participatory research (CBPR): Towards equitable involvement of community in psychology research. The American psychologist, 73, 884-898. https://doi.org/10.1037/amp0000167

Cortina, L. M., Curtin, N., \& Stewart, A. J. (2012). Where is social structure in personality research? Psychology of Women Quarterly, 36, 259-273. https://doi.org/10.1177/0361684312448056

Crenshaw, K. (1989). Demarginalizing the intersection of race and sex: A Black feminist critique of antidiscrimination doctrine, feminist theory and antiracist politics. University of Chicago Legal Forum, 140, 139-167.

Devos, T., \& Banaji, M. R. (2005). American = White? Journal of personality and social psychology, 88, 447-466. https://doi.org/10.1037/0022-3514.88.3.447

Dupree, C. H., \& Boykin, C. M. (2021). Racial inequality in academia: Systemic origins, 
modern challenges, and policy recommendations. Policy Insights from the Behavioral and Brain Sciences, 8, 11-18. https://doi.org/10.1177/2372732220984183

Emerson, K. T., \& Murphy, M. C. (2014). Identity threat at work: How social identity threat and situational cues contribute to racial and ethnic disparities in the workplace. Cultural Diversity and Ethnic Minority Psychology, 20, 508-520. https://doi.org/10.1037/a0035403

Espinosa, P., \& Verney, S. P. (2020). The underutilization of community-based participatory research in psychology: A systematic review. American Journal of Community Psychology, 1-15. https://doi.org/10.1002/ajcp.12469

Feinstein, J. S. (1993). The relationship between socioeconomic status and health: A review of the literature. The Milbank Quarterly, 71, 279. https://doi.org/10.2307/3350401

Fetvadjiev, V. H., \& van de Vijver, F. J. R. (2015). Measures of personality across cultures. In G. J. Boyle, D. H. Saklofske, \& G. Matthews (Eds.), Measures of personality and social psychological constructs (pp. 752-776). Elsevier Academic Press. https://doi.org/10.1016/B978-0-12-386915-9.00026-7

García Coll, C. G., Lamberty, G., Jenkins, R., McAdoo, H. P., Crnic, K., Wasik, B. H., \& Garcia, H. V. (1996). An integrative model for the study of developmental competencies in minority children. Child Development, 67, 891-914. https://doi.org/10.2307/1131600

Gibby, R. E., \& Zickar, M. J. (2008). A history of the early days of personality testing in American industry: An obsession with adjustment. History of Psychology, 11, 164-184. https://doi.org/10.1037/a0013041

Glymour, M. M., \& Manly, J. J. (2008). Lifecourse social conditions and racial and ethnic 
patterns of cognitive aging. Neuropsychology Review, 18, 223-254.

https://doi.org/10.1007/s11065-008-9064-z

Golash-Boza, T. M. (2016). Race \& racisms: A critical approach. New York, NY: Oxford University Press.

Hall, G. C., Yip, T., \& Zárate, M. A. (2016). On becoming multicultural in a monocultural research world: A conceptual approach to studying ethnocultural diversity. American Psychologist, 71, 40-51. https://doi.org/10.1037/a0039734

Hartmann, W. E., Kim, E. S., Kim, J. H., Nguyen, T. U., Wendt, D. C.,Nagata, D. K., \& Gone, J. P. (2013). In search of cultural diversity, revisited: Recent publication trends in crosscultural and ethnic minority psychology. Review of General Psychology, 17, 243-254. http://dx.doi.org/10.1037/a0032260

Henderson, D. (1997). Intersecting race and gender in feminist theories of women's psychological development. Issues in Mental Health Nursing, 18, 377-393, https://doi.org/10.3109/01612849709009420

Henrich, J., Heine, S. J., \& Norenzayan, A. (2010). The weirdest people in the world? Behavioral and Brain Sciences, 33(2), 1-75. https://doi.org/doi:10.1017/S0140525X0999152X

Hoggard, L. S., Byrd, C. M., \& Sellers, R. M. (2012). Comparison of African American college students' coping with racially and nonracially stressful events. Cultural Diversity and Ethnic Minority Psychology, 18, 329-339. https://doi.org/10.1037/a0029437

Hoggard, L. S., Byrd, C. M., \& Sellers, R. M. (2015). The lagged effects of racial discrimination on depressive symptomology and interactions with racial identity. Journal of Counseling Psychology, 62, 216-22 
Institute of Social Science Survey, Peking University (2015) China Family Panel Studies (Peking University; V41) [Survey Data] https://doi.org/10.18170/DVN/45LCSO,

Joo, Jae Seon. (2007-2016) Korean Longitudinal Survey of Women and Families (KOSSDA A1CUM-0029; V1.0) [Dataset]. KOSSDA. http://hdl.handle.net/20.500.12236/23806

Khwaja, M., Vaid, S. S., Zannone, S., Harari, G. M., Faisal, A. A., \& Matic, A. (2019).

Modeling personality vs. Modeling personalidad: In-the-wild mobile data analysis in the five countries suggests cultural impact on personality models. Proceedings of the ACM on Interactive, Mobile, Wearable and Ubiquitous Technologies (IMWUT), 3(3), 1-24. https://doi.org/10.1145/3351246

King, L. (2021, July 9, 16, \& 23). Discussion on Personality Psychology and Marginalized Communities [Conference presentation]. ARP 2021 Convention, Online. www.tinyurl.com/ARP2021KingBooker

King, L., Lee, K., \& Kaleem, J. (2020, June 5). George Floyd's death and the National Conversation: Pain, Anger and Hope. Los Angeles Times. https://www.latimes.com/world-nation/story/2020-06-05/george-floyds-death-sparksvoices-on-americas-deep-pain-and-searing-rage.

Kuper, N., Modersitzki, N., Phan, L. V., \& Rauthmann, J. F. (2021). The dynamics, processes, mechanisms, and functioning of personality: An overview of the field. British Journal of Psychology, 112, 1-51. https://doi.org/10.1111/bjop.12486

Leong, F. T. L., Leung, K., \& Cheung, F. M. (2010). Integrating cross-cultural psychology research methods into ethnic minority psychology. Cultural Diversity and Ethnic Minority Psychology, 16, 590-597. https://doi.org/10.1037/a0020127

Lui, P. P., Rollock, D., Chang, E. C., Leong, F. T., \& Zamboanga, B. L. (2016). Big 5 
personality and subjective well-being in Asian Americans: Testing optimism and pessimism as mediators. Asian American Journal of Psychology, 7, 274-286. https://doi.org/10.1037/aap000005

Manly, J. J., Jacobs, D. M., Touradji, P., Small, S. A., \& Stern, Y. (2002). Reading level attenuates differences in neuropsychological test performance between African American and White elders. Journal of the International Neuropsychological Society: JINS, 8, 341-348. https://doi.org/10.1017/s1355617702813157

Manstead, A. S. (2018). The psychology of social class: How socioeconomic status impacts thought, feelings, and behaviour. British Journal of Social Psychology, 57, 267-291. https://doi.org/10.1111/bjso.12251

Markus, H. R. (2008). Pride, prejudice, and ambivalence: Toward a unified theory of race and ethnicity. American Psychologist, 63, 651-670. https://doi.org/10.1037/0003-066x.63.8.651

Markus, H. Z, Coe, C. L., Ryff, C. D., Karasawa, M., Kawakami, N., and Kitayama, S. (20092010) Survey of Midlife in Japan (MIDJA) (ICPSR 30822) [NACDA] https://doi.org/10.3886/ICPSR34969.v4

Matsumoto, D., Kudoh, T., \& Takeuchi, S. (1996). Changing patterns of individualism and collectivism in the United States and Japan. Culture \& Psychology, 2, 77-107. https://doi.org/10.1177/1354067x9621005

McAdams, D. P. (1995). What do we know when we know a person? Journal of Personality, 63, 365-396. https://doi.org/10.1111/j.1467-6494.1995.tb00500.x https://doi.org/10.1146/annurev.psych.093008.100507

McAdams, D. P., \& Pals, J. L. (2006). A new Big Five: Fundamental principles for an integrative 
science of personality. American Psychologist, 61, 204-217.

https://doi.org/10.1037/0003-066X.61.3.204

Milner, H. R. (2007). Race, culture, and researcher positionality: Working through dangers seen, unseen, and unforeseen. Educational Researcher, 36, 388-

400. https://doi.org/10.3102/0013189X07309471

Morency, J.-D., MacIsaac, S., \& Malenfant, É. C. (2017, February 23). Immigration and diversity: Population projections for Canada and its regions, 2011 to 2036 immigration and diversity. Statistics Canada. https://www150.statcan.gc.ca/n1/pub/91-551-x/91-551x2017001-eng.htm.

Mullings, L., \& Schulz, A. J. (2006). Intersectionality and Health: An Introduction. In A. J. Schulz \& L. Mullings (Eds.), Gender, race, class, \& health: Intersectional approaches (p. 3-17). Jossey-Bass/Wiley.

Muthukrishna, M., Henrich, J., \& Slingerland, E. (2021). Psychology as a historical science. Annual Review of Psychology, 72, 717-749. https://doi.org/10.1146/annurevpsych-082820-111436

Nguyen, T. T., Criss, S., Michaels, E. K., Cross, R. I., Michaels, J. S., Dwivedi, P., Huang, D., Hsu, E., Mukhija, K., Nguyen, L. H., Yardi, I., Allen, A. M., Nguyen, Q. C., \& Gee, G. C. (2021). Progress and push-back: How the killings of Ahmaud Arbery, Breonna Taylor, and George Floyd impacted public discourse on Race and racism on Twitter. SSM Population Health, 15, 100922. https://doi.org/10.1016/j.ssmph.2021.100922

Ong, A. D., Burrow, A. L., Fuller-Rowell, T. E., Ja, N. M., \& Sue, D. W. (2013). Racial microaggressions and daily well-being among Asian Americans. Journal of Counseling Psychology, 60, 188-199. https://doi.org/10.1037/a0031736 
Ong, A. D., Fuller-Rowell, T., \& Burrow, A. L. (2009). Racial discrimination and the stress process. Journal of Personality and Social Psychology, 96, 12591271. https://doi.org/10.1037/a0015335

Plaks, J. E., Malahy, L. W., Sedlins, M., \& Shoda, Y. (2012). Folk beliefs about human genetic variation predict discrete versus continuous racial categorization and evaluative bias. Social Psychological and Personality Science, 3, 31-39. https://doi.org/10.1177/1948550611408118

Quintana, S. M. (2007). Racial and ethnic identity: Developmental perspectives and research. Journal of Counseling Psychology, 54, 259-270. https://doi.org/10.1037/00220167.54.3.259

RAND. (n.d.) The Indonesian Family Life Survey (IFLS). https://www.rand.org/well-being/social-and-behavioral-policy/data/FLS/IFLS.html

Rentfrow, P. J., Gosling, S. D., \& Potter, J. (2008). A Theory of the Emergence, Persistence, and Expression of Geographic Variation in Psychological Characteristics. Perspectives on psychological science: a journal of the Association for Psychological Science, 3, 339369. https://doi.org/10.1111/j.1745-6924.2008.00084.x

Rentfrow, P. J., \& Jokela, M. (2016). Geographical psychology: The spatial organization of psychological phenomena. Current Directions in Psychological Science, 25(6), 393398. https://doi.org/10.1177/0963721416658446

Roberts B. W. (2007). Contextualizing personality psychology. Journal of personality, 75, 1071-1081. https://doi.org/10.1111/j.1467-6494.2007.00467.x

Roberts, S. O., Bareket-Shavit, C., Dollins, F. A., Goldie, P. D., \& Mortenson, E. (2020). Racial 
inequality in psychological research: Trends of the past and recommendations for the future. Perspectives on Psychological Science, 15, 1295-1309. https://doi.org/10.1177/1745691620927709

Rohner, R. P. (1984). Toward a conception of culture for cross-cultural psychology. Journal of Cross-Cultural Psychology, 15, 111-138. https://doi.org/10.1177/0022002184015002002

Saucier, G., \& Thalmayer, A. G. (2012). Cultural, contextual, and measurement challenges for the paradigm of personality science. Handbook of Personality at Work. https://doi.org/10.4324/9780203526910.ch36

Seaton, E. (2019). Racial discrimination and racial identity: Daily moderation among Black youth. American Psychologist, 74. https://doi.org/10.1037/amp0000367

Seaton, E. K., \& Douglass, S. (2014). School diversity and racial discrimination among AfricanAmerican adolescents. Cultural Diversity and Ethnic Minority Psychology, 20, 156165. https://doi.org/10.1037/a0035322

Seaton, E. K., Gee, G. C., Neblett, E., \& Spanierman, L. (2018). New directions for racial discrimination research as inspired by the integrative model. American Psychologist, 73, 768-780. https://doi.org/10.1037/amp0000315

Silan, M. (2020, September 8-10). Rethinking multi-site studies: Can the cross-indigenous approach remedy common cross-cultural vulnerabilities? [Conference presentation]. Psychological Science Accelerator Conference. https://videos.files.wordpress.com/dfYdMDUb/sept-8-3a_dvd.mp4

Suh, E. M. (2002). Culture, identity consistency, and subjective well-being. Journal of Personality and Social Psychology, 83, 1378-1391. https;//doi.org/10.1037/00223514.83.6.1378 
Sullivan, D. (2020). Social Psychological Theory as History: Outlining the Critical-Historical Approach to Theory. Personality and Social Psychology Review, 24, 78-99. https://doi.org/10.1177/1088868319883174

Syed, M., \& Kathawalla, U. (2020). Cultural psychology, diversity, and representation in open science. https://doi.org/10.31234/osf.io/t7hp2

Syed, M., Santos, C., Yoo, H. C., \& Juang, L. P. (2018). Invisibility of racial/ethnic minorities in developmental science: Implications for research and institutional practices. American Psychologist, 73, 812-826. https://doi.org/10.1037/amp0000294

Syed, M. (2021, February 05). Where are race, ethnicity, and culture in personality research? [Preprint submitted for review]. https://doi.org/10.31234/osf.io/m57ph

Thalmayer, A. G., Job, S., Shino, E. N., Robinson, S. L., \& Saucier, G. (2020). ‡Ūsigu: A mixed-method lexical study of character description in Khoekhoegowab. Journal of personality and social psychology. https://doi.org/10.1037/pspp0000372

Thalmayer, A. G., Toscanelli, C., \& Arnett, J.J. (2021). The neglected 95\% revisited: Is American psychology becoming less American? American Psychologist, 76, 116-129 https://doi.org/10.1037/amp0000622

Utsey, S. O., Giesbrecht, N., Hook, J., \& Stanard, P. M. (2008). Cultural, sociofamilial, and psychological resources that inhibit psychological distress in African Americans exposed to stressful life events and race-related stress. Journal of Counseling Psychology, 55, 4962. https://doi.org/10.1037/0022-0167.55.1.49

van de Vijver F. J. (2013). Contributions of internationalization to psychology: toward a global and inclusive discipline. The American psychologist, 68, 761-770. https://doi.org/10.1037/a0033762 
van de Vijver, F. J., Leung, K., \& Leung, K. (1997). Methods and data analysis for crosscultural research (Vol. 1). Sage.

Williams, M. J., \& Eberhardt, J. L. (2008). Biological conceptions of race and the motivation to cross racial boundaries. Journal of Personality and Social Psychology, 94, 10331047. https://doi.org/10.1037/0022-3514.94.6.1033

Williams, D. R., Mohammed, S. A., Leavell, J., \& Collins, C. (2010). Race, socioeconomic status, and health: complexities, ongoing challenges, and research opportunities. Annals of the New York Academy of Sciences, 1186, 69-101. https://doi.org/10.1111/j.17496632.2009.05339.x

Willroth, E. C., Atherton, O. E., \& Robins, R. W. (2021). Life satisfaction trajectories during adolescence and the transition to young adulthood: Findings from a longitudinal study of Mexican-origin youth. Journal of Personality and Social Psychology, 120, 192205. https://doi.org/10.1037/pspp0000294

Winter, D.G., \& Barenbaum, N.B. (1999). History of modern personality theory and research. In L. A. Pervin \& O. P. John (Eds.), Handbook of personality: Theory and research (2nd ed., pp. 3-27). New York: Guilford Press. 